\title{
GROWTH POLE CYCLES: A SYNTHESIS OF GROWTH POLE AND LONG WAVE THEORIES*
}

Orley M. Amos, Jr."

\section{Introduction}

The growth pole paradigm, a widely discussed regional topic in the 1960s and 1970s, has fallen into disrepute in the 1980s. Reasons for this include the problems Richardson identified when he stated that "Much of the growth pole literature has been confusing, repetitious, riddled with misinterpretations of the ideas of others, descriptive rather than analytical, and weak in theory (Richardson, 1976, p. 1)." The growth pole paradigm has also been tarnished by the failure of many growth center development strategies in the U.S. and other countries (Martin, 1978). Chaotic theory, limited empirical support, and unsatisfactory policy record are sufficient to send most theories into disregard, including the growth pole paradigm.

Amid the theoretical confusion, the growth pole paradigm does capture several fundamental, if ill-defined, dimensions of societal development. Evidence of this is provided by the number of scholars who have identified similar concepts contained in this paradigm. Gaile discussed the long list who have examined the spread-backwash concept using different terminology, stating that "Indeed, spread-backwash, generative-parasitic, and trickling-downpolarization should be considered to be synonymous concepts (Gaile, 1980, p. 18)." In the context of leading firms Thomas noted that "...a number of concepts found in Perroux's recent writings on growth poles, such as 'leading firms,' 'leading industries,' and 'points of growth,' are synonymous with what used to be called 'the dominant economic unit (Thomas, 1972, p. 54).' Thomas further indicated that "Perroux's propulsive and key industries have a strong input-output flavor. Indeed, he defines some of the salient characteristics of these industries within an industrial complex analysis (Thomas, 1972, p. 55)." The inconsistencies in terminology has resulted from the diversity of objectives, concerns, and backgrounds of the scholars

\footnotetext{
'Presented at the Southern Regional Science Associationmeetings, April 28, 1989, Chapel Hill, North Carolina. The research for this paper was conducted in cooperation with the Southwest Regional Development Center, College of Business Administration, Oklahoma State University.

"Professor of Economics and Kerr Professor of Economic Development, Oklahoma State University.
}

contributing to this topic, making it clear why Richardson argued that the topic is "confusing" and "riddled with misinterpretations".

The task of this analysis is not to revive, per se, the growth pole paradigm from its current state of demise, but to reinterpret the basic explanatory framework. The working proposition of this research is that the growth pole paradigm, although capturing critical aspects of societal development, is incomplete. Noting Richardson's concern "...that effective regional spatial planning requires a 15-25 year time horizon is inconsistent with abandoning growth pole policies within a decade (Richardson, 1976,p. 1)," the argument is made that the growth pole process lasts, not mere decades, but centuries. Even the 25-year time horizon desired by Richardson for policy evaluation encompasses only part of the growth pole process.

It is also argued that existing growth pole theories view the development process too narrowly. Although. Friedmann's theory of growth poles is concerned with societal "'development' ...characterized as an innovation process leading to the structural transformation of social systems (Friedmann, 1972, p. 84)," where "...innovations may be technical or institutional and, if the latter, may be usefully subsumed under the customary categories of social, economic, political and cultural (Friedmann, 1972, p. 86)," he is the exception to the rule. Most analysis takes an economic production perspective, as indicated by Thomas, "I prefer to restrict my comments here to an examination of the economic and geographical concepts associated with the more 'traditional' notion of growth poles (Thomas, 1972, p. 53)." While partial analysis of components in a larger system is important, failure to widen the perspective to consider the larger system is inherently incomplete.

The general view of socio-economic development presented in this paper is also a central focus of Rasmussen (1990), Flammang (1990), and Malizia (1990), contained in this volume. Extending the earlier work by Flammang (1979), that delineated the differences between the terms growth and development, this compilation of papers stresses the importance of taking the broader view of development that includes structural changes in society, rather than the narrower view of growth that includes increased production within the existing structure.

The objective of this paper is to present a more general theory of spatio-temporal development that en- 
compasses the prominent features of the growth pole paradigm, but has a broader scope, more fundamental structure, and more powerful explanatory capability. The enhanced nature of this theory is possible by synthesizing the spatial features of the growth pole paradigm, with temporal features of a similar, but distinct, theory of endogenous economic cycles. This objective is pursued in three steps. First, the key components of the growth pole and long wave theories are highlighted, with preacknowledgement that neither contain the formal details of other discussions. Second, a preliminary synthesis of the growth pole and long wave theories is examined, providing an improved, but also incomplete, theory of spatio-temporal development. Third, a general theory of socio-economic development is presented by integrating the growth pole paradigm with a utility-based behavioral explanation of long waves.

\section{A Summary of the Growth Pole Process}

The growth pole process can be divided into three stages: 1) concentration at a single center, 2) diffused concentration at multiple centers, and 3) diffusion to the periphery. These three stages are indicated by Richardson's (1978) summary of the spatial growth pattern:

\begin{abstract}
Historically, the economic development of nations tends to conform to predictable spatial patterns: initial polarization in one or two regions, a process that becomes cumulative in the most rapid industrialization phase; subsequent diffusion of development to other regions; spatial concentration within each region in a limited set of major urban centres; and eventually (a relatively recent phenomenon) spatial readjustment within these urban areas as economic and social change promotes decentralization. (Richardson, 1978, p. 155)
\end{abstract}

The first stage is triggered by the introduction of innovations, which play a key role in Perroux's (1955) discussion of growth poles. Although Perroux emphasized the importance of technological innovations leading to the creation of new industries, Friedmann (1972) used the more general view of innovations as the "successful introduction of ideas or artifacts perceived as new into a given social system (Friedmann, 1972,p. 87)," including changes in technical or institutional (economic, political, and cultural) dimensions of society. Although technical innovation is a key determinant of economic growth, Friedmann's general view of innovation captures the underlying mechanism driving socio-economic development used in this analysis.
The introduction of an innovation leads to the creation of a motor industry. The initial stage of this process leads to concentration of activity in the growth pole and a single, geographically concentrated growth center. The existence of agglomeration economies, increasing returns, urbanization economies, and nonzero transportation costs dictate that the initial emergence of the growth pole necessarily coincides with a single growth center.

While the terms "pole" and "center" are apparently synonymous in the first stage, as the growth pole enters the second stage, a critical distinction between the two terms arises. Richardson indicates that "Some like to draw a distinction between 'growth pole' and 'growth centre', using the former to refer to industrial or sectoral activities and the latter to mean the urban concentrations where these activities are localized (Richardson, 1978, p. 164fn)." Although Perroux originally discussed growth poles in abstract economic space, emphasizing industrial rather than spatial linkages, it has since been adapted to the dimensions of geographic space, especially for policy applications, with concentrated urban areas identified as growth centers. Using the terms interchangeably in reference to urban areas, in all but the first stage, has contributed to misunderstanding and confusion.

In the second stage the growth pole becomes geographically dispersed, creating multiple growth centers. In this stage the growth pole becomes an industrial complex containing numerous distinct growth centers integrated into an urban hierarchy. The growth pole expansion, exhibiting a pattern of diffused concentration, operates through the urban hierarchy, with diffusion of the innovation through the urban hierarchy occurring simultaneously with increased concentration of growth centers at lower levels in the hierarchy. Each growth center is a counterpart of the original growth center, but temporally lagged due to the diffusion through the central place hierarchy, with only a limited degree of diffusion into the periphery occurring.

The first two stages of this process are termed the backwash or polarization effect in the growth pole literature. The existence of a negative backwash effect on the periphery, as described by Richardson $(1976$, p. 3$)$, is less important than the concentration of activity occurring in the growth pole and growth centers. In this context the term polarization, emphasizing the relative growth of the growth pole and growth centers, is preferred to the term backwash, emphasizing the absolute decline in the periphery.

Widespread innovation diffusion occurs in the third stage with growth centers diffusing the innovation to the surrounding peripheries. The term periphery refers to all areas not integrated with the growth pole and growth centers, rather than merely rural areas surrounding growth centers. The diffusion process entails factors noted for the 
growth pole spread effect, including the opening of new markets, utilizing peripheral resources, etc. In this stage the peripheries grow relatively faster than the centers.

Transportation plays a central role in these three stages. In the first stage, attempts by the motor and ancillary industries to minimize transportation costs leads to concentration of the growth pole in a single growth center, and induces improvements in transportation systems within the growth center. Expansion of the growth pole to multiple growth centers, in the second stage, induces the development of transportation systems that reduce costs and improve transportation efficiency within and among growth centers. In the final stage, diffusion into the periphery induces the reduction of transportation costs between the centers and the peripheries. While the first two stages induce transportation system innovations that reinforce growth pole concentration, the third stage induces transportation innovations that facilitate dispersion. ${ }^{1}$

\section{Endogeneity of the Growth Process}

Schumpeter (1939, pp. 161-174) argued that economic cycles are stimulated by the introduction of innovations, with different cycle lengths attributable to different types of innovations. Building on previous work, he identified three cycles with varying durations: Kitchin, 35 years; Juglar, 7-11 years; and Kondratieff, 45-60 years. Each cycle contains the same four phases: prosperity, recession, depression, and recovery, with the first two phases comprising the upswing and the latter two the downswing. The introduction and implementation of innovations generate a recovery that, due to multiplicatively reinforcing growth, overshoots the long run, sustainable equilibrium. The over productive surge causes the prosperity phase to eventually diminish into a recession. And overreaction during adjustment back to the long run equilibrium generates a depression. Schumpeter attempted to endogenize the cyclical process by arguing that the downswing of one cycle induces a clustering of innovations that stimulates the upswing of the next cycle. However, Kuznets (1940) argued that Schumpeter did not successfully demonstrate the necessary clustering of innovations needed for endogeniety.

In the context of Kondratieff cycles, or long waves, several scholars have dealt with Schumpeter's innovation clustering deficiency. Mensch (1979) argued that innovations are qualitatively different in each of the long wave phases, being process-oriented in the prosperity and recession phases and product-oriented in the depression and recovery phases. The former innovations are primarily aimed at improving the existing production operations and the latter lead to the development of substantially new products.
Van Duijn (1983) built on Mensch's analysis to develop an endogenous theory of long waves with product innovations clustering during the downswing of one long wave. Among this cluster of innovations are one or more major product innovations, such as the internal combustion or the steam engines, that stimulate extensive private capital and public infrastructure investment, leading to widespread social, economic, and cultural changes that Flammang (1990) termed "niche changing." The innovations, following a product life-cycle pattern of introduction, growth, maturity, and decline, cause aggregate production stimulated through innovation-inducing private and public capital investment to follow a similar pattern. A correspondence thus exists between Schumpeter's four phases and the four innovation life-cycle phases: recovery (introduction), prosperity (growth), recession (maturity), and depression (decline).

A key extension of the Mensch/van Duijn explanation is that long wave downswings induce a variety of socio-economic innovations, where the term innovation is consistent with Friedmann's (1972) use that includes both technical and institutional changes in society. Although Mensch and van Duijn were primarily concerned with technological innovations, Booth (1986) argued that product innovations are one type of general entrepreneurial business activities induced by long wave downswings and process innovations are one type of managerial activities induced by long wave upswings. Amos (1989a) and Amos and Currier (1989) extend this further, arguing that long waves generate two alternating periods of society-wide socio-economic behavior. Evolutionary behavior, including process innovations and managerial business activity, tries to maintain the status que during the upswing of a long wave. Revolutionary behavior, including product innovations and entrepreneurial business activity, tries to change the status quo, being most pronounced in the depression phase of the long wave downswing.

\section{A General Theory of Spatio-Temporal Development}

The growth pole paradigm of regional analysis and the long wave theory of economic cycles have numerous similarities, which is understandable since both analyze the long run development of society from different perspectives. Growth pole theories examine spatial relationships and long wave theories highlight temporal relationships of this phenomenon. The purpose of this analysis is to synthesize the two, arguing that both theories have been met with skepticism when viewed independently, but when combined they provide a better, and more powerful, explanation of spatio-temporal development. 


\section{A Coincident Growth Pole-Long Wave Process}

The simplest synthesis of growth pole and long wave theories is also the most obvious. Given that the introduction of innovations stimulates both the growth pole and long wave processes, it is logical to argue that the polarization and spread effects of the growth pole process are the spatial embodiment of four phases of the long wave process. From this perspective, the introduction of innovations stimulates both the long wave recovery phase and the onset of the polarization effect. Increasing growth rates at the pole, and falling or relatively low rates in the periphery, lead to a moderate but rising economy-wide growth rate found in the recovery phase. In the long wave prosperity phase the polarization effect continues as diffused-concentration causes rapid growth throughout the pole and relatively high growth rates economy-wide. In the long wave recession phase, growth at the pole diminishes and the spread effect begins diffusing innovations throughout the periphery. The growth stimulation ceases in the depression phase, with the complete diffusion of innovations throughout the periphery ending the spread effect. This process is cyclical because the depression phase induces revolutionary socioeconomic behavior that stimulates new innovations causing both the growth pole and long wave processes to start again.

\section{A Long Wave Inducing Growth Pole Process}

A major deficiency in this simple synthesis is the failure to consider transportation, which is important to the interaction between growth pole, growth centers, and peripheries. In the early polarization phase of the growth pole process transportation systems are developed that improve in the efficiency of intra-center distribution. As the growth pole generates multiple growth centers, the impetus changes to improving inter-center transportation systems. The spread effect generating diffusion to the periphery then induces improvements in economy-wide transportation systems.

Transportation also plays a key role in the long wave process. Mensch (1979) and van Duijn (1983) indicate "major" product innovations are characterized by extensive investment in private and public infrastructure capital, especially transportation systems, including canals, railways, highways, airports, and public utilities. In fact, long wave proponents have argued that 50 -year economic cycles are due to the lengthy time lags associated with the rates of production and depreciation of public infrastructure capital.

However, long wave theorists have tended to lump public infrastructure capital into a single category. Within the context of growth poles, twotypes of public infrastructure and transportation systems emerge: concentration and dispersion. Concentration infrastructure facilitates the agglomeration of economic activity, including urban streets, urban transportation systems, and urban public utilities. Dispersion infrastructure facilitates the society-wide distribution of goods, services, resources, and information, including interstate highways, intercontinental railroads, airplanes, and long distance communication. The former type of infrastructure improves intra-center distribution and the latter improves center-periphery distribution.

The importance of transportation implies that the growth pole process, rather than the spatial embodiment of long waves, actually generates long waves due to differential types of public infrastructure capital induced by the polarization and spread effects. During the polarization phase, innovations that stimulate the growth pole process also trigger concentration infrastructure that generates one complete polarization long wave, traversing Schumpeter's four cycle phases. The depression phase of the 50-year polarization long wave signals the end of the polarization phase of the growth pole process and the beginning of the spread phase.

The long wave depression phase induces product innovations that stimulate the next long wave. The polarization effect is replaced by the spread effect as the long wave depression induces innovations based on diffusion into the periphery. The long wave generated by the innovation of dispersive infrastructure needed for the spread effect is a spread long wave. Although the depression phase may induce the implementation of relatively new inventions, it may also induce the re-implementation of existing innovations into a new use. Innovations stimulating the polarization long wave may be "re-innovated" and adapted to dispersion infrastructure that facilitates the distribution from the centers to the peripheries.

Extrapolating van Duijn's (1983, p. 143) designations and considering the problems of exact timing of a long run process overshadowed by short run occurrences, approximate long wave periods for the past two hundred years can be specified as: $1772-1836,1836-1883,1883$ 1937 , and 1937-1982. ${ }^{2}$ Two major technological innovations during this period, the steam and internal combustion engines, fit the pattern of concentration and dispersion infrastructure. The steam engine, invented in 1769 , was applied to industrial production that stimulated the long wave from 1772 to 1836 . The steam engine was then adapted to the railroad in 1825 , an innovation which fueled the long wave from 1836 to 1883 . The polarization long wave was based on the concentration of activity into urban areas, and the spread long wave was based on the use of railroads in the dispersion of development into the peripheries during the mid-1800s.

The internal combustion engine, following a similar pattern, was invented in 1885 and first used for intra-urban 
automobile transportation, fueling the long wave from 1883 to 1937 . The automobile found new life after the depression and World War II, through the expansion of the interstate highway system, which triggered the most recent long wave from 1937 to 1982 . The internal combustion engine was used for concentration infrastructure within urban areas in the polarization long wave and dispersion infrastructure in the spread long wave. This analysis indicates that long waves are not only generated by the growth pole process, but are also a key component of the process. The depression of one long wave provides the underlying socio-economic behavioral inducement to undertake major product innovations, with the growth pole process determining the concentration or dispersion form of the innovation.

However, a key factor, an explanation of the impetus for this process, is missing. A truly comprehensive, endogenous theory of spatio-economic development must not only describe the mechanism in which innovations are diffused throughout society, but explain how the process begins.

\section{Hierarchial Needs and the Growth Pole Cycle}

In previous works (Amos, 1989a, 1989b; Amos and Currier, 1989) the foundations for a hierarchial needs theory of long waves was developed, arguing that long waves are induced by the process of satisfying hierarchial needs. The relative satisfaction of one level in the hierarchy of needs leads to the emergence of a new, higher need. The emergence of each higher need stimulates product innovations best suited for its satisfaction. Synthesizing this view of long waves with the growth pole theory generates a general theory of spatio-temporal development.

The existence of an unfulfilled need motivates society to pursue activities that provide its satisfaction, e.g., hungry people search for food. The pervasiveness of an unfulfilled need, and the inventive intelligence of humanity, imply that new and better methods of satisfying an unfulfilled need will be sought and developed. Although many "inventions" may occur, only the best suited for the satisfaction of the dominant unfulfilled need are implemented as innovations. Once the need is relatively satisfied, then it no longer motivates innovative activity, and a new need emerges. Clearly the basic need for food in the early stages of civilization induced innovations in agricultural production, including cultivation and the domestication of livestock, that occurred before innovations in other production activities aimed at higher needs. The sequential emergence-satisfaction-emergence process of hierarchial needs drives society to higher levels of development.
Given that needs are hierarchial, the lowest need in the hierarchy will initiate the process. This is far from a trivial point, in that previous long wave and growth pole theories fail to identify a suitable starting point. In many cases the starting point is the industrial revolution. However, there is no reason to think that human behavior was fundamentally different in 1900 than it was in 1400 . In the context of hierarchial needs, the development process, and by inference the growth pole and long wave cycles, is initiated with the dawn of civilization. Support for the pervasiveness of general long runcyclical activity is offered by Snyder who states "...the Mayans in Central America held festivals to ward off calamity that occurred in a 54year cycle, the Bible tells of 50-year jubilees in which old debts were forgiven, and there is some evidence of a 50 year cycle of war and inflation in the Roman Empire." (Snyder, 1984, p. 4)

The existence or emergence of a prevalent need dominates societal behavior, dictating the types of socioeconomic activity best suited for its satisfaction. Existing inventions are implemented or new inventions are induced and implemented that best suit the dominant need. Resources are allocated, or reallocated, to the production of the goods suited for this need. The greater the unfulfillment, the more society directs its efforts toward this production. Production of goods increase because they are profitable, and they are profitable because they satisfy society's unfulfilled need. ${ }^{3}$

Spatial constraints, i.e., nonzero transportation costs, dictate that production activity is initially concentrated, first at a single center, then at multiple centers. Expansion is a limited, diffused concentration process, as the growth pole expands into multiple growth centers. The existence of the unfulfilled need sets the production process in motion. The fact that the production process is initially characterized by the concentration of activity is determined by the spatial dimensions of production, reaching a point of satiation within the growth pole, and thus stimulating the economy through a long wave cycle due to infrastructure used in the polarization effect of the growth pole process.

The onset of the depression phase of the polarization long wave induces further innovation activity that is characterized by the dominant need. The peripheries of the growth centers remain relatively untouched by the expansion occurring in the polarization long wave, since innovations diffused within the growth centers. The dominant need in the peripheries remains unfulfilled inducing activity suited to its satisfaction. Since the basic products have existed since the preceding long wave, the peripheral needs are best satisfied through improved distribution made possible 
by improved inter-economy transportation systems. This sets in motion the spread long wave as infrastructure is developed to distribute production from the growth centers to the peripheries.

The growth pole process is complete when the spread long wave runs its course in conjunction with the dispersive transportation systems. The completion of the growth pole process occurs with the relative satisfaction of the dominant need. However, the satisfaction of this need allows a new, higher need to emerge, which initiates the growth pole-long wave process once more, dictating a different set of innovations and production activity. This process continues as long as new needs emerge.

The introduction of hierarchial needs into the growth pole-long wave process implies an interesting facet of societal development. The growth pole process is not a singular occurrence, containing one polarization long wave followed by one spread long wave. This analysis indicates that the growth polecycle is a recurrent process, triggered by the emergence and re-emergence of hierarchial needs. Each time a need emerges from the hierarchy, the growth pole process and two separate long waves are stimulated.

There is also reason to suspect that the growth pole cycle is periodic, with each cycle lasting approximating 100 years. Amos and Currier (1989) argue that long waves are 50 years in duration due to the intergenerational reproduction of the population every 25 years. One generation, raised during 25 years of evolutionary behavior in the upswing of a long wave, triggers the onset of a revolutionary period also lasting 25 years. The next generation, raised during revolutionary behavior in the downswing of a long wave, triggers the onset of the new evolutionary period. Given that one long wave contains two 25-year periods, and one growth pole cycle contains two long waves, growth pole cycles recur at approximately 100-year intervals. ${ }^{4}$

\section{A Model of the Growth Pole Cycle}

The first step to a formal model of the growth pole cycle is possible by extending the utility based model of long waves in Amos (1989b). The synthesis of growth pole and long wave theories indicates that the following components are important for this model: hierarchial needs, production of specific goods for each hierarchial need, differential polarization and spread effects, infrastructure investment, and aggregate production.

The key implication for this analysis is the cyclical, sequential pattern exhibited by the utility deficit, $\Phi_{\mathrm{i}}$, the degree to which each need $i$ is unfulfilled. Figure 1, panel A, adapted from Amos (1989b), illustrates the pattern displayed by the utility deficit for each need. As $\Phi_{\mathrm{i}}$ increases the motivation to satisfy the underlying need also increases, inducing innovations aimed at the production of the need specific good, $X_{i}$. However, the society-wide motivation to produce $X_{i}$ occurs only when $\Phi_{i}>\Phi_{i-1}$. This sets the wheels of production in motion and initiates the growth pole polarization effect. The overall production of $X_{i}$ is indicated by the pattern contained in panel B. Production of $X_{i}$ increases until $\Phi_{i}<\Phi_{i+1}$, at which point the economy begins to reallocate goods to the production of $X_{i+1}$. It should be noted that the shape of the utility deficit curve is unrelated to the shape of $\Phi_{i}$, i.e., the peak of $\Phi_{i}$ is not necessarily at the inflection of the $X_{i}$. The critical relationship is that each $\mathrm{X}_{\mathrm{i}}$ begins with the intersection of two $\Phi_{i}$ curves and declines at the next intersection when $X_{i+1}$ begins production. ${ }^{5}$

Panel $C$ illustrates the polarization and spread effects resulting from the production of $\mathbf{X}_{\mathrm{i}}$, captured in an aggregate marginal product measure for the resources in the growth pole and periphery regions. The polarization effect occurs up to the inflection point of the $\mathbf{X}_{1}$ curve, where agglomeration economies and increasing returns are exhausted. The spread effect then sets in, leading to relative equality between the marginal product variables for both regions.

Resources in the pole and periphery play an important role in the shapes of the marginal product curves. The spatial concentration of resources determines where the growth pole establishes the initial growth center. The growth pole/center emerges in the region with the cheapest and mostaccessible resourcesused to produce $X_{i}$. Expansion into secondary growth centers down the urban hierarchy is directed by the need for additional resources. The marginal product curve for the pole in panel $\mathrm{C}$ peaks due, in general, to the diminishing marginal productivity of these resources. Expansion into the periphery is thus stimulated during the spread effect by the need for additional resources.

The marginal product curve of the periphery increases after the inflection point of $\mathrm{X}_{i}$ in panel $\mathrm{B}$ is reached. At this point expansion by the growth pole stimulates marginal productivity of the periphery. ${ }^{6}$ The marginal product curve of the periphery rises to a peak, then converges toward to the marginal product curve of the pole. The marginal product curve of the periphery remains below that of the pole due to the less accessible, more expensive, and less productive resources in the periphery.?

Resources are also important as a new growth pole emerges in conjunction with a new need. Given then each need is satisfied by a particular good with specific characteristics, resources used to produce each good, $\mathbf{X}_{i}$, are likely to differ. This differential demand for resources, together with the spatial concentration of resources and exhaustion of the cheapest, most accessible resources in 


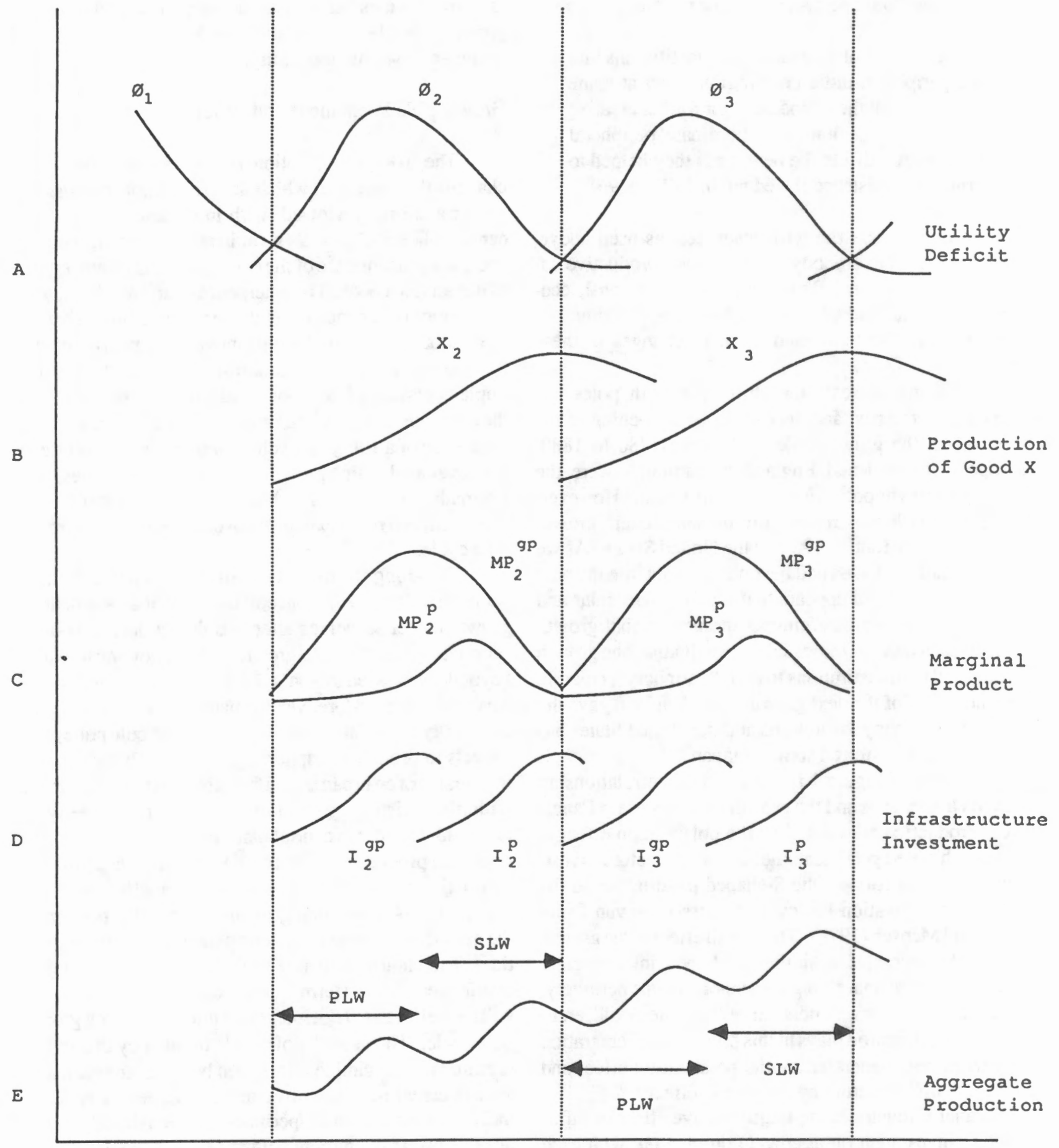

Figure One. Growth Pole Cycle and Long Waves 
the production $\mathrm{X}_{\mathrm{i}-1}$, implies that the growth pole for $\mathrm{X}_{\mathrm{i}}$ is likely to emerge in a new location.

Friedmann provided further reasoning for the shift of growth poles from one cycle to the next, stating:

In the process of extending their institutions into the periphery, older core regions may at some point exhaust their capacities for further creative response and decline to a subordinate, peripheral position relative to the new cores they helped to bring into existence (Friedmann, 1972, p. 96).

In this context the term resources, as used above, should be taken to embody the combined productive capacity of society, including technical, institutional, economic, political, and cultural, analogous to Friedmann's application of the term innovation to changes in these varied facets of society.

On a global scale the shift in growth poles has happened in the past and appears to be happening in the present. In the growth pole cycle from 1780 to 1880 , Europe in general and England in particular were the dominant growth poles in the western world. However, this growth pole was replaced in the subsequent growth pole cycle from 1880 to 1980 by the United States. As we move toward the 1990 s and beyond, entering into the next growth pole cycle, it appears that Japan in particular and Asia in general are emerging as the new global growth pole. In each case, as indicated by Friedmann, one growth pole shifted their institutions to their "periphery", creating the emergence of the next growth pole. England gave the United States many institutions and the United States has subsequently transferred some to Japan.

Panel D of Figure 1 illustrates the interrelationship between long waves and the growth pole process in Panels A-C. Production stimulated by the polarization effect in the growth pole cycle, generates an infrastructure investment curve that follows the S-shaped pattern, due to the underlying innovation life-cycle discussed by van Duijn (1983) and Mensch (1979). The spread effect of the growth pole cycle generates a similar S-shaped infrastructure investment curve underlying dispersion into the periphery. The infrastructure investment curves indicate the differential role transportation plays in this process. Concentration infrastructure is generated by the polarization effect and dispersion infrastructure by the spread effect.

Panel E illustrates the multiplicative effect of infrastructure investment on aggregate production, with each growth pole cycle generating two complete long waves. The pattern of aggregate economic activity depicted in panelE is what most long wave scholars studied. However, it should be emphasized that this is only the end result of a series of interrelated activities, beginning with the emergence of unfulfilled hierarchial needs.

\section{Implications of the Growth Pole Cycle}

The theory presented in this paper generates important implications for societal development, including the growth pole phenomena, the long wave phenomena, and social and regional inequality.

\section{Growth Pole Phenomena and Policies}

The 100-year duration of the growth pole cycle changes the manner in which the growth pole process has been traditionally viewed, with implications for growth center policies. This analysis indicates that the growth pole cycle is a consequence of the emergence and re-emergence of hierarchial needs. The emergence of an unfulfilled need sets in motion a series of fundamental, structural changes throughout society, including innovations, growth centers, transportation systems, and resource utilization. The implementation of technological innovations stimulates the emergence of new and/or expanded urban areas. Over the course of a 100 -year cycle new transportation systems are developed to link growth centers and peripheries, both internally and externally. New resources are discovered, exploited, and often exhausted over the course of a growth pole cycle.

The long term nature of this process echoes Richardson's (1976) concern that the abandonment of growth center strategies after less than a decade is inappropriate. An effective growth pole policy must extend beyond even Richardson's 15-25 year time horizon to several decades. Moreover, the natural process implied by this theory brings into question any growth pole policy that expects to promote peripheral growth merely by expanding the size of an urban area. If the policy is not coordinated with the existing growth pole cycle, the underlying hierarchial need, the central place hierarchy diffusion, the dominant production activity, and the resources utilized in that activity, then it will be relatively ineffective. The stimulation of a potential growth center that is not part of the growth pole cycle is fighting against an overwhelming tide. The natural tendency of this process should not be overlooked. A short term, quick fix, urban area stimulation will be ineffective if not integrated into the existing growth pole cycle. The growth pole cycle implied by this theory is more than the simple interaction between an urban area growth center and the surrounding rural periphery. Each individual growth center/periphery relationship is part of a larger, powerful, ongoing pattern of development.

\section{Long Wave Phenomena}

The growth pole cycle also offers insight into the analysis of long waves, a topic that has been held in low regard by many scholars. A key criticism of long wave 
theories has been the lack of endogeneity, with any apparent periodic pattem attributed to exogenous shocks. Mensch and van Duijn provided insight into the endogeneity of technological innovations underlying the long wave stimulation. However, they suggested, but stopped short of identifying, the underlying behavioral motivation, and ultimate cause, of the whole process - unfulfilled hieranchial needs. Moreover, the inclusion of hierarchial needs, together with the spatial concentration of resources, indicates long waves are not directly stimulated by hierarchial needs, but are merely a consequence of the growth pole process. Long waves have been hard to quantitatively pin down, because the spatial dimension dictated by the growth pole cycle expands the sizeand location of the "economy" experiencing the long waves. A given nation is unlikely to exhibit a clear, unambiguous long wave pattern due to the shift of growth pole from one cycle to the next.

\section{Social and Regional Inequality}

Alonso (1980) discussed five key phenomenon associated with the development process that were often considered separately-Kuznets' (1955) social inequality, Williamson's (1965)regional inequality, economic growth, urban concentration, and demographic transition. In that each depicted bell-shaped, or inverted-U, patterns he speculated on an underlying and unidentified correspondence between them. This theory provides insight into the correspondence.

A pattern of rising and falling economic growth is clearly implied by the analysis in Figure 1. Each long wave is essentially a bell-shaped pattern of accelerating and decelerating rates of economic growth. This analysis further implies that the growth rates will be spatially differentiated during the polarization and spread long waves with respect to the growth pole and periphery. Differential regional growth rates are central to the study of unbalanced regional growth, and thus regional income inequality.

Regional inequality clearly follows a bell-shaped pattern over the course of a single growth pole cycle, as graphically depicted by the difference between the marginal product curves in panel $\mathbf{C}$ of Figure 1. The polarization long wave, generating concentration at the growth centers, also generates increased regional inequality, while the spread long wave, dispersing the fruits of innovation and development, generates decreased regional inequality. Empirical evidence of the most recent growth pole cycle supports this contention. A measure of regional inequality adapted from Williamson (1965) ${ }^{8}$ is presented in Figure 2. This figure indicates that after 46 years of decline, from 1932 through the 1978, consistent with the most recent spread long wave, regional inequality in the U.S. has been increasing. The incidence of rising regional inequality since 1978 is consistent with the onset of a new polarization long wave. A study of intrastate regional inequality in the U.S. by Amos (1988) also provides evidence of increasing inequality in the 1970 s consistent with the onset of a new growth pole cycle.

A bell-shaped for social inequality is also implied by panel Cof Figure 1. Concentration in the polarization long wave generates rising social inequality and dispersion in the spread long wave reduces social inequality. Evidence indicates that social inequality, measured by the Gini coefficient, also began increasing in the 1970s after declining since the 1940s.

Geographic concentration also follows a bell-shaped pattern according to the analysis in Figure 1, with the polarization long wave leading to an increasing rate of geographic concentration and the dispersion long wave leading to a decreasing rate of geographic concentration.

Although direct implications for the demographic transition are not evident from Figure 1, a better understanding of the interaction between the other four bellshapes is provided by the growth pole cycle. It indicates that regional inequality, social inequality, and geographic concentration are not simple, bell-shaped curves, but recurrent, cyclical patterns lasting approximately 100 years. Economic growth is also periodic, lasting 50 years. Further study of the consistency between each of Alonso's five bell-shaped curves and the growth pole cycle is clearly in order.

\section{Conclusion}

The spatio-temporal theory of growth pole cycles presented in this paper is an attempt to synthesize two related, but distinct, theories of societal development. Obvious room for improvement, expansion, and refinement exists. A more rigorous model needs to be explored and precise linkages between structural variables need to be obtained. However, the theory presented provides insight into long run development that is unavailable in existing theories. The broad sweep of the theoretical structure developed implies important, overlooked interactions between apparently unrelated facets of society. This theory can not yet be labeled a general theory of socio-economic behavior, but it is a step in that direction.

This analysis also provides further insight into the distinction between growth and development discussed by Flammang (1979) and examined by the three companion papers in this volume (Rasmussen (1990), Flammang (1990), and Malizia (1990)). The growth pole cycle provides structure to Flammang's (1990) argument that economic growth and development can be characterized as niche filling or niche changing, respectively. The depressions 


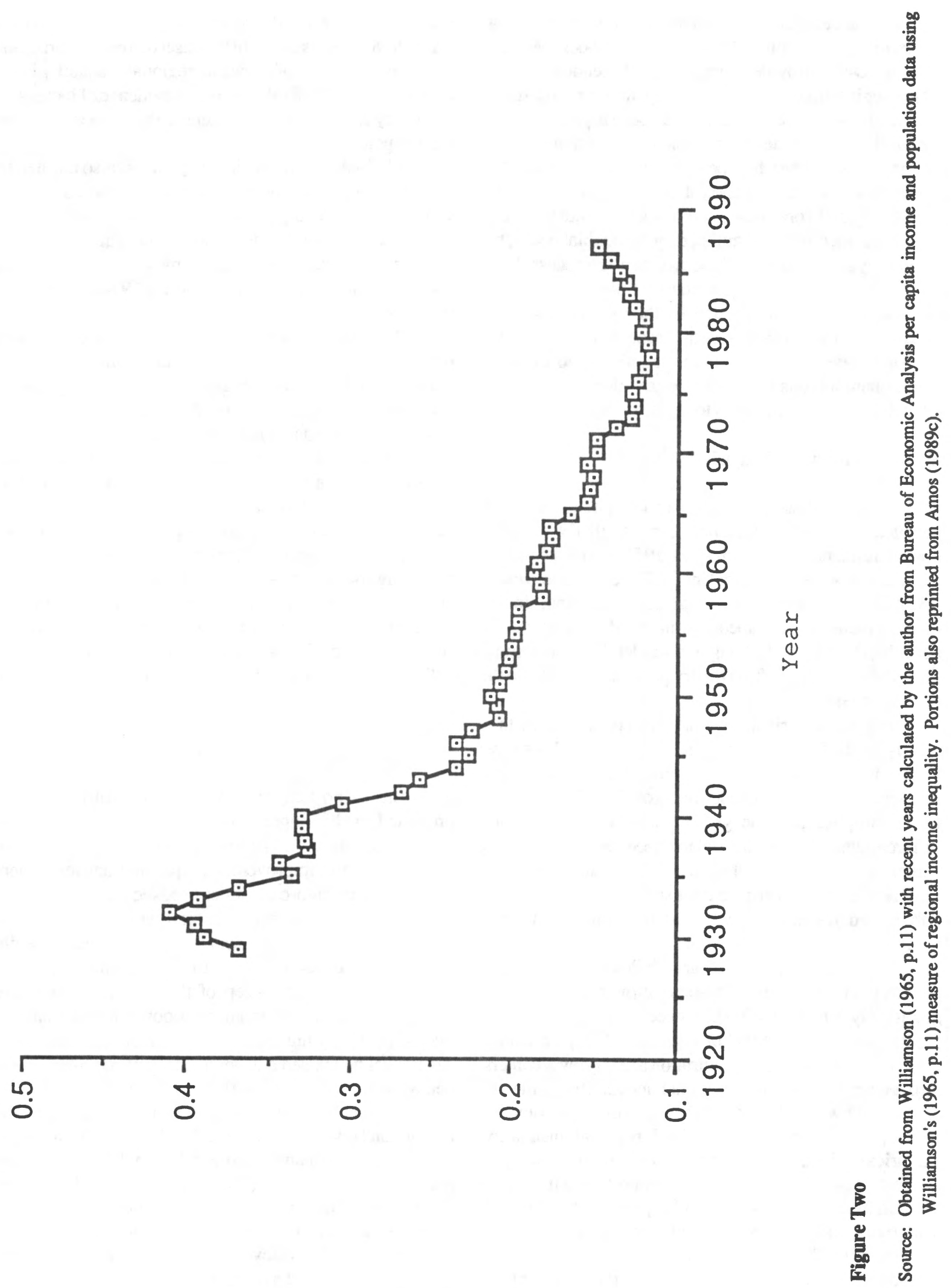


of the polarization and spread long waves of the growth pole cycle induces revolutionary behavior, entrepreneurial activity, and product innovations that generate Flammang's "softening" of the economy. These periods are characterized by major structural changes that lead to new niches and provide the impetus for the advancement of economic development. The prosperity phases of the polarization and spread long waves induce evolutionary behavior, managerial activity, and process innovations that underlie Flammang's "hardening" of the economy, in which the niches are filled and economic growth, as typically measured, occurs.

This analysis indicates that growth and development at the metropolitan level, as examined by Malizia (1990), must be considered in the light of not only current national trends, but secular, global trends. The growth of a rural, Kansas community is more interrelated with on Japanese activity than typically thought, as each growth pole cycle stimulates development through the global urban hierarchy. Moreover, this analysis indicates that typical measures of development, especially per capita gross output and income inequality, as discussed by Rasmussen (1990), are cyclical as the level of development progresses. A "negative trend" in these measures is not a decline in development, but a "niche change" as society achieves a higher level of development.

\section{Notes}

'As noted by North (1955) transportation, especially efforts to improve transportation, plays a key role in regional development. However, little recognition of the differential types of transportation systems has been apparent.

${ }^{2}$ According to van Duijn there have been four long waves since the late 1700 's. Although van Duijn remains consistent with Schumpeter (1939) and measures the four long waves fro prosperity through recovery $(1782-1845,1845-1892,1892-1948$, and 1948-present, probably ending in 1992), this analysis measures each long wave from recovery to depression, since the recovery signals the initial effect of the innovation activity and the depression captures the end of the life-cycle process.

This concept can be extended to include the inducement of all types of socio-economic innovations, including institutional, political, and cultural activities. In a political sense, governments rule at the discretion of the governed. Although dictatorial government can repress society, in the long run they repress only when society continues to permit it and are overthrown when society decides to change. In this context, governments, laws, regulations, and social institutions, as emphasized by Friedman (1972), are innovations of society. The innovations will be used by society as long as they fulfill society's needs and will be replaced when they do not.
The invention of the steam engine in 1769 and the internal combustion engine in 1885 , as discussed above, is indicative of this interval. This implies that a major invention first used for concentration infrastructure, then applied to dispersion infrastructure, would be indicated for 1670 and again in 1980 . Although no major technological innovations surface in 1670 that readily fit the criteria, it is worth noting that Isaac Newton discovered the law of gravity in the 1660 s, a major scientific "invention" with widespread implications. Moreover, major breakthroughs in magnetic superconductor technology have been occurring in the 1980s. Prognosticators suggest the application of superconductor technology to computers, energy storage and distribution, and magnetic levitation trains. Innovations based on the first two would be consistent with the polarization long wave, and are likely to be implemented first, and the third application would be consistent with a spread long wave, and probably will not be seen for several decades.

Ignored in Panel B is the lag between the time $\Phi_{i}>\Phi_{i-1}$ and the initial production of $\mathbf{X}_{i}$. In reality the production of $X_{i}$ will lag behind the emergence of the need $i$, perhaps by a decade or more, due to the recognition in the new need and constraints restricting the reallocation of resources from $X_{i-1}$ to $X_{i}$. Ignoring this lag does not materially affect the analysis.

The periphery marginal product curve in Panel $\mathrm{C}$ captures the essence of the net spillover effect identified by Richardson's (1976, p. 3) Figure 1c. The marginal product curve in this analysis reflects the slope of the Richardson's net spillover curve. Moreover, elimination of the negative backwash effect for the periphery identified by Richardson does not significantly affect this analysis.

${ }^{7}$ Agglomeration economies, internal economies of sale, and urbanization economies play critical roles in the relative productivity of the pole and periphery. The pole is relatively more productive with the onset of the growth pole because it has a comparative advantage over the periphery in the production of this good. The comparative advantage is due to resource concentration, and economies associated with the spatial concentration of capital and production activities. The less concentrated periphery will not achieve the marginal productivity exhibited by the pole, even though it will close the gapduring the spread effect.

The measure of regional income inequality is estimated using the equation originally employed by Williamson (1965, p. 11):

$$
V_{i}=\frac{\sqrt{\sum_{j=1}^{n}\left(Y_{i j}-Y_{i}\right)^{2} \frac{f_{i j}}{N_{i}}}}{Y_{i}}
$$

where: $Y_{i j}=$ per capita income in area $j$ of region $i, Y_{i}=$ per capita income in region $i, f_{i j}=$ population in area jof state $i$, and $N_{i}=$ total population in region $i$. This equation is used to estimate regional inequality among counties within each state and among states within the U.S. 


\section{References}

Alonso, William. "Five Bell Shapes in Development." Regional Science Association Papers. 45 (1980). 5-16.

Amos, Orley M. "Unbalanced Regional Growth and Regional Income Inequality in the Latter Stages of Development." Regional Science and Urban Economics. 18 (1988). 549566.

"A Re-evaluation of Long Cycle Theories: Development as the Satisfaction of Hierarchial Needs." Social Science Quarterly. 70 (1989a). 341-355.

"The Micro-Foundations of Long Waves: Implications of a Hierarchial Utility Function." Presented at the Southern Economic Association, Orlando, Florida, November, 19. 1989b.

"An Inquiry into the Causes of Increasing Regional Income Inequality in the United States." The Review of Regional Studies. 19 (1989c). Forthcoming. . and Kevin M. Currier. "The Foundations of a Hierarchial Theory of the Long-Wave Phenomenon." Southern Economic Journal. 56 (1989). 142-156.

Booth, Douglas E. "Long Waves and Uneven Regional Growth." Southern Economic Journal. 53 (1986). 448-460.

Flammang, Robert A. "Economic Growth and Economic Development: Counterparts or Competitors?" Economic Development and Cultural Change. 28 (1979). 47-61.

"Development and Growth Revisited." Review of Regional Studies. 20 (1990).

Friedmann, John. "A General Theory of Polarized Development." In Niles M. Hansen (ed.). Growth Centers in Regional Economic Development. New York: The Free Press, 1972. 82-107.

Gaile, D. L. "The Spread-Backwash Concept." Regional Studies. 14 (1980). 15-25.

Kuznets, Simon. "Schumpeter's Business Cycles." American Economic Review. 30 (1940). 257-271.

"Economic Growth and Income Inequality." American Economic Review. 45 (1955). 1-28.

Malizia, Emil E. "Economic Growth and Economic Develop- ment: Concepts and Measures." Review of Regional Studies. 20 (1990).

Martin, Randolph C. "An Empirical Inquiry into the Effectiveness of the Growth Center Approach." The Review of Regional Studies. 8 (1978). 1-19.

Mensch, Gerhard. Stalemate in Technology. Cambridge: Ballinger Publishing Company, 1979.

North, Douglas C. "Location Theory and Regional Economic Growth." Journal of Political Economy. 58 (1955). 243258.

Perroux, Francois. "Note sur la notion de 'pole de croissance?" Economie Appliqee. (1955). 307-320. Translated as "Note on the Concept of Growth Poles and reprinted in D. McKee, R. Dean, and W. Leahy (eds.). Regional Economics: Theory and Practice. New York: The Free Press, 1970. 93-104.

Rasmussen, David W. "Development as a Positive Concept." Review of Regional Studies. 20 (1990).

Richardson, Harry W. "Growth Pole Spillovers: The Dynamics of Backwash and Spread." Regional Studies. 10 (1976). 1 9.

Regional Economics. Urbana, Illinois: University of Illinois Press, 1978.

Schumpeter, Joseph A. Business Cycles: A Theoretical. Historical, and Statistical Analysis of the Capitalist Process. Volumes I andII. New York: McGraw-Hill Book Company, Inc., 1939.

Snyder, John M. "Introduction." In Kondratieff, Nikolai D. The Long Wave Cycle, 1926. Translated by Guy Daniels. New York: Richardson and Snyder, 1984.

Thomas, Morgan D. "Growth Pole Theory: An Examination of Some of its Basic Concepts." In Niles M. Hansen (ed.). Growth Centers in Regional Economic Development. New York: The Free Press, 1972. 50-81.

van Duijn, Jacob J. The Long Wave in Economic Life. London: George Allen and Unwin, 1983.

Williamson, Jeffery G. "Regional Inequality and the Process of National Development: A Description of the Patterns." Economic Development and Cultural Change. 13 (1965). 345. 